\title{
Platelet testing in flow diversion: a review of the evidence
}

\author{
L. Ian Taylor, BS, ${ }^{1}$ James C. Dickerson, BA, ${ }^{1}$ Robert J. Dambrino, BS, ${ }^{1}$ \\ M. Yashar S. Kalani, MD, PhD, ${ }^{2}$ Philipp Taussky, MD, ${ }^{2}$ Chad W. Washington, MS, MD, MPHS, ${ }^{3}$ and \\ Min S. Park, MD2
}

${ }^{1}$ University of Mississippi Medical Center, Jackson, Mississippi; ${ }^{2}$ Department of Neurosurgery, Clinical Neurosciences Center, University of Utah, Salt Lake City, Utah; and '3epartment of Neurosurgery, University of Mississippi Medical Center, Jackson, Mississippi

\begin{abstract}
OBJECTIVE Although the use of dual antiplatelet therapy with flow diversion is recommended and commonplace, the testing of platelet inhibition is more controversial.

METHODS The authors reviewed the medical literature to establish and describe the physiology of platelet adhesion, the pharmacology of antiplatelet medications, and the mechanisms of the available platelet function tests. Additionally, they present a review of the pertinent neurointerventional and interventional cardiology literature.

RESULTS Competing reports in the neurointerventional literature argue for and against the use of routine platelet function testing, with adjustments to the dosage or medications based on the results. The interventional cardiology literature has also wrestled with this dilemma after percutaneous coronary interventions, with conflicting reports of the benefits of platelet function testing.

CONCLUSIONS Despite its prevalence, the benefits of platelet function testing prior to flow diversion are unproven. This practice will likely remain controversial until the level of evidence improves through more rigorous testing and reporting.

https://thejns.org/doi/abs/10.3171/2017.3.FOCUS1746
\end{abstract}

KEY WORDS flow diversion; percutaneous coronary interventions; dual antiplatelet therapy; platelet function testing

$\mathrm{S}$ INCE the approval of the Pipeline embolization device (PED; Medtronic) by the US Food and Drug Administration in 2011, flow diversion has become a much more common and accepted treatment modality for both the originally intended large and giant cerebral aneurysms of the cavernous and paraclinoid internal carotid arteries and for aneurysms that would fall outside the initially approved indications.

Because of the prothrombotic nature of bare metal stents placed within the vasculature, thromboembolic events and in-stent thrombosis are significant risks associated with flow-diverting stents (FDSs). This necessitates the use of peri- and postprocedural dual antiplatelet therapy (APT). Current dosage recommendations are based primarily on the literature from cardiology and interventional radiology, with most studies utilizing a combination of 100-325 $\mathrm{mg}$ of aspirin and $75 \mathrm{mg}$ of clopidogrel daily, beginning 7-10 days preoperatively. ${ }^{1}$ Clopidogrel therapy typically continues for 3-6 months or more, while aspirin therapy is often continued indefinitely. Although dual APT has been shown to reduce the rate of thromboembolic events, it may also contribute to increased rates of complications.

Mitigating the risks of thromboembolic and hemorrhagic events is, therefore, of the utmost concern in the management of patients treated with FDSs. The use of platelet function testing (PFT) has been proposed as a possible solution to ensure an appropriate level of reduction in platelet activation and aggregation to minimize the risk of these adverse outcomes. Herein, we review the methodology, indications, and efficacy of PFT after flow diversion through a review of the most current medical literature.

ABBREVIATIONS ADP = adenosine diphosphate; APT = antiplatelet therapy; FDS = flow-diverting stent; GP-Ilb/Illa = glycoprotein Ilb/lla; GRAVITAS = Gauging Responsiveness with A VerifyNow Assay_-Impact on Thrombosis and Safety; LTA = light transmission aggregometry; PED = Pipeline embolization device; PFT = platelet function testing; PRU = P2Y12 reaction unit; TEG = thromboelastography; TXA2 = thromboxane $A_{2}$.

SUBMITTED February 1, 2017. ACCEPTED March 10, 2017.

INCLUDE WHEN CITING DOI: 10.3171/2017.3.FOCUS1746. 


\section{Pharmacology of Platelet Adhesion and Antiplatelet Medications}

\section{The Role of Platelets in Hemostasis}

Under normal physiological conditions, thrombus formation begins when platelets adhere to exposed subendothelial collagen by binding von Willebrand factor at the site of vascular injury. Collagen-induced platelet activation causes platelets to de-granulate, releasing prothrombotic mediators, including adenosine diphosphate (ADP) and fibrinogen. ${ }^{44}$ ADP released from platelets binds platelet receptors $\mathrm{P} 2 \mathrm{Y} 1$ and $\mathrm{P} 2 \mathrm{Y} 12$ and amplifies platelet response to other agonists, including thrombin; it also increases intracellular release of calcium, further potentiating platelet activation. ${ }^{39}$ Collagen activation increases platelet production and release of thromboxane $\mathrm{A}_{2}$ (TXA2), which activates platelet glycoprotein IIb/IIIa (GP-IIb/IIIa) receptors. Once activated, GP-IIb/IIIa receptors bind fibrinogen, leading to aggregation and plug formation through platelet-fibrinogen cross-linking. Once the primary platelet plug is formed, secondary hemostasis takes place via the coagulation cascade to stabilize the platelet plug though the formation of an insoluble fibrin clot. ${ }^{44}$

The invasive nature of endovascular procedures guarantees some level of increased platelet activation, and therefore increased risk of thrombosis, through this mechanism of endothelial damage and subendothelial matrix exposure. In the case of stenting and flow diversion procedures, this risk is further amplified by the introduction of bare metal devices into the vascular lumen. It has been demonstrated that platelet damage from shear forces as well as direct contact with the stent surface can cause platelet activation. ${ }^{23,25}$ For these reasons, FDS manufacturer recommendations and the standards of care dictate the use of dual APT before and after device implantation to reduce the risk of in-stent thrombosis and thromboembolic events.

\section{Pharmacology of Antiplatelet Medications}

Antiplatelet medications are favored for use in conjunction with FDSs for their ability to reduce platelet aggregation and thrombus formation, particularly in the arterial circulation, where anticoagulant agents are less effective. The most common dual APT regimen in use today is a combination of aspirin and clopidogrel. Aspirin, an irreversible COX-1 inhibitor, prevents the intraplatelet conversion of arachidonic acid to TXA2 for the life of the platelet. By decreasing the production and, therefore, the total amount of TXA2 released by platelets, activation of GP-IIb/IIIa receptors is reduced, resulting in decreased platelet aggregation.

Clopidogrel, an irreversible platelet P2Y12 receptor antagonist, prevents activation of the receptor by ADP. Reduced P2Y12 receptor activation leads to decreases in platelet aggregation, dense granule release, and GP-IIb/ IIIa activation. Clopidogrel, a prodrug, requires extensive metabolism by CYP enzymes, particularly CYP2C19.44 For this reason, the levels of active metabolite can be affected by drug-drug interactions as well as genetic variability.

In instances in which clopidogrel is not used in dual
APT or is believed to be ineffective, it is often replaced by another P2Y12 receptor antagonist, such as prasugrel or ticagrelor. Prasugrel, an irreversible P2Y12 inhibitor, also requires hepatic metabolism; however, prasugrel is more potent and appears to be less affected by genetic variations in P450 enzymes than clopidogrel. ${ }^{20,35}$ Ticagrelor is a reversible P2Y12 inhibitor that does not require hepatic metabolism, but, unlike clopidogrel and prasugrel, which directly bind and inhibit P2Y12 receptors, ticagrelor acts on an allosteric site to prevent ADP-induced conformational change of the receptor. ${ }^{44}$

Triple APT, described in the cardiology literature, involves the addition of cilostazol, a selective inhibitor of phosphodiesterase III, to the standard dual APT regimen. This combination has been shown to be both effective and safe, with particular benefits noted in patients with diabetes. ${ }^{2,32}$ However, the use of 3 antiplatelet agents has not been described in the neurointerventional literature. In addition to modifications to the traditional aspirin and P2Y12 inhibitor combination, single-drug therapies such as the GP-IIb/IIIa inhibitors abciximab and tirofiban have been described. In the setting of PED, tirofiban has several proven benefits, including a good safety profile, reversibility in a matter of hours, cost effectiveness compared with other GP-IIb/IIIa inhibitors, and no need for PFT. ${ }^{11}$

\section{Antiplatelet Drug Resistance}

Determining the true rates of antiplatelet drug resistance in the general population is a difficult task, largely because of variations in testing methodologies and defining resistance. Reported rates of aspirin resistance have varied widely in PFT assays, but studies that have specifically measured levels of COX-1 acetylation or thromboxane $\mathrm{B}_{2}$ in the blood have failed to detect significant rates of aspirin resistance in healthy individuals when compliance is ensured. ${ }^{9,21,31,41,42}$ In studies on clopidogrel, resistance is most commonly defined as high on-treatment platelet reactivity to ADP by the P2Y12 receptor, indicating limited platelet inhibition. Given the variability of the PFT assays employed and their respective cut-off values for defining high on-treatment platelet reactivity, reported rates of clopidogrel resistance have varied from as low as $16 \%$ to as high as $50 \%$. $^{33}$

Resistance to clopidogrel has been primarily attributed to genetic mutations and drug-drug interactions. Clopidogrel is a prodrug that must undergo extensive metabolism by the enteric and hepatic systems, including CYP enzymes. Genetic polymorphisms affecting these enzymes, particularly CYP2C19, have a significant impact on individual clopidogrel efficacy, as CYP2C19 is involved in both steps of the oxidative metabolism of clopidogrel. ${ }^{6,26,29}$ Because of this reliance on CYP enzymes, it follows that drugs known to cause CYP inhibition can have similar effects on the metabolism of clopidogrel. Genetic mutations in the $A B C B 1$ gene, which encodes a P-glycoprotein efflux pump involved in absorption of clopidogrel, have also been implicated in clopidogrel resistance, as has the concomitant use of drugs that interfere with these pumps, most notably proton pump inhibitors. ${ }^{10}$

Prasugrel and ticagrelor are known to be more potent 
inhibitors of P2Y12 than clopidogrel, and multiple studies have demonstrated improved outcomes and greater overall response to these drugs compared with clopidogrel. ${ }^{47,48}$ Although this is certainly encouraging, there remains a small, but not insignificant, portion of the population in whom a therapeutic response to these drugs will fail to be achieved.

\section{Platelet Function Testing}

Using PFT to measure the extent of platelet inhibition in patients receiving APT has been considered a potential solution to the problem of clopidogrel resistance. Because each currently available test targets a specific pathway in the multistep process of platelet adhesion, activation, and aggregation, no single test has yet proven to be clearly superior, which may explain the large number of platelet function tests currently available. What follows is a brief, but by no means comprehensive, introduction to the most commonly used platelet function tests. These tests do, however, represent the overwhelming majority of those used in the currently available literature.

Light transmission aggregometry (LTA) is widely considered the gold-standard platelet function assay. LTA detects platelet aggregation after the addition of ADP to platelets by measuring the change in light transmittance. Despite its wide availability and good correlation between results and adverse events, it has limited reproducibility. Additionally, the process of centrifugation required to separate the platelets makes this test time consuming. ${ }^{19} \mathrm{~A}$ similar test of platelet aggregometry is multiple electrode aggregometry, which detects platelet aggregation in whole blood after ADP-induced activation based on changes in electrical impedance. Advantages of multiple electrode aggregometry include its relative speed and the ability to use whole blood. ${ }^{37}$

VerifyNow (Accumetrics) is a bedside assay that involves ADP stimulation of platelets in whole blood that bind to fibrinogen-coated polystyrene beads. As these platelet-bead complexes fall out of solution, the change in light transmittance is measured to assess the level of aggregation. This test has become increasingly popular as it is a fully automated bedside system that eliminates the need for experienced laboratory technicians..$^{27,37}$

The platelet function analyzer (PFA-100) test attempts to mimic certain in vivo conditions. PFA-100 measures the time required for occlusion of the apparatus by platelet plugs under high shear rates while reproducing the pressure of the capillary in vivo. Activation of platelets is achieved by coating the walls of the membrane with collagen and ADP. ${ }^{30}$ This test has the advantages of short processing time, use of whole blood, and the re-creation of in vivo thrombus formation. However, results are highly dependent on the level of von Willebrand factor present. Additionally, it has a low sensitivity for assessing the level of clopidogrel-induced inhibition, potentially reducing the clinical utility of this assay.7,3

The thromboelastography (TEG) hemostasis analyzer measures platelet-fibrin clot strength. Multiple protocols exist, but the methodology typically involves induction of platelet-fibrin clots by reptilase and Factor XIIIa, followed by the addition of ADP, to assess the contribution of the P2Y12 receptor to the clot formation process. ${ }^{24}$ Although TEG tests multiple aspects of thrombus formation, as well as the interaction between platelets and the coagulation cascade, there remains a lack of standardization and a paucity of studies available to assess the predictive value of adverse effects based on TEG. ${ }^{5,15}$

\section{PFT in the Neurosurgical and Neurointerventional Literature}

\section{Studies Supporting the Use of PFT}

Studies examining antiplatelet use during stent-assisted coiling of intracranial aneurysms have suggested that the degree of platelet inhibition is related to the development of ischemic lesions on follow-up MRI scans. ${ }^{49}$ Likewise, studies supporting the use of PFT cite results indicating that hypo- or hyperresponse to clopidogrel is associated with increased rates of complications in patients after PED placement (Table 1). In 2013, Delgado Almandoz et al. ${ }^{16}$ published the results of a retrospective, single-center study of 44 patients undergoing PED placement with the goal of identifying optimal preprocedure P2Y12 reaction unit (PRU) values as reported by VerifyNow testing. Most patients were started on a standard dual APT regimen of aspirin and clopidogrel 10 days before the procedure, and PFT was carried out the day before the scheduled procedure, with a target PRU range of 80-200. Clopidogrel hyporesponders (PRU > 200) were switched to prasugrel, whereas hyperresponders (PRU < 80) received clopidogrel doses at increasing intervals until target PRU values were achieved. In this cohort, all 4 of the major perioperative thromboembolic and hemorrhagic complications following PED placement occurred in patients determined to be hyporesponsive to clopidogrel (PRU > 200), all of whom then received either changes to their dose or alternative P2Y12 antagonists. Based on this cohort, the strongest independent predictor of all and major perioperative thromboembolic and hemorrhagic complications after PED placement was a preprocedure PRU value of $<60$ or $>240$.

The following year, Delgado Almandoz et al.$^{17}$ reported findings from another retrospective, single-center study of 100 patients undergoing endovascular treatment of unruptured cerebral aneurysms-including but not limited to PED placement-with a goal of assessing the extent of variability in patient response to clopidogrel and the frequency of "delayed conversion" to a hyperresponse to clopidogrel. They performed PFT using VerifyNow and set a target PRU range of 60-240. Using extensive followup testing, they found a significant decrease in mean PRU values with continued administration of a standard 75mg daily clopidogrel dose. After 8-9 doses, there was a mean PRU of 137, whereas after 30 doses, the same cohort demonstrated a mean PRU of 59. The authors also found that $59 \%$ of patients who were not initially considered hyperresponders experienced a delayed conversion to hyperresponsiveness in follow-up testing. Additionally, a hyperresponse to clopidogrel was associated with a significantly higher risk of a major hemorrhagic event than was observed in those who did not exhibit hyperresponse (11\% vs $0 \%$ ). Conversely, a hyporesponse to clopidogrel was as- 
TABLE 1. Summary of selected articles from the neurointerventional literature

\begin{tabular}{lllclll}
\hline \multicolumn{1}{c}{ Authors \& Year } & \multicolumn{1}{c}{ Methodology } & $\begin{array}{c}\text { Level of } \\
\text { Evidence }\end{array}$ & $\begin{array}{c}\text { No. of } \\
\text { Patients }\end{array}$ & $\begin{array}{c}\text { Endovascular } \\
\text { Intervention(s) }\end{array}$ & $\begin{array}{c}\text { Type of PFT } \\
\text { Used }\end{array}$ & $\begin{array}{c}\text { Data Support } \\
\text { Preprocedural PFT Use }\end{array}$ \\
\hline Chandra, 2013 & Expert opinion & E & - & Various & Various & No \\
\hline Comin \& Kallmes, 2013 & Literature review & E & - & Various & Various & No \\
\hline Delgado Almandoz et al., 2013 & Retrospective, single-center & C & 44 & PED & VerifyNow & Yes \\
\hline Delgado Almandoz et al., 2014 & Retrospective, single-center & C & 100 & Various & VerifyNow & No \\
\hline Faught et al., 2014 & Multicenter survey & E & - & Various & Various & No \\
\hline Gandhi et al., 2014 & Expert consensus & E & - & Various & Various & No \\
\hline Brinjikji et al., 2015 & Retrospective, multicenter & B-NR & 793 & PED & Various & No \\
\hline Flechtenmacher et al., 2015 & Prospective, single-center & C & 107 & Intra- \& extracra- & VerifyNow, Multi- \\
plate, \& LTA & nial stenting & TEG & Yes \\
\hline McTaggart et al., 2015 & Prospective, single-center & C & 31 & PED & Multiplate & Yes \\
\hline Oran et al., 2015 & Retrospective, single-center & C & 100 & PED & VerifyNow & ADP inhibition \\
\hline Tan et al., 2015 & Retrospective, single-center & C & 74 & PED & Various & Yes \\
\hline Raychev et al., 2016 & Retrospective, single-center & C & 45 & PED & No \\
\hline Skukalek et al., 2016 & Review \& meta-analysis & C & 1110 & PED & PED \\
\hline
\end{tabular}

NR = nonrandomized; $-=$ not applicable (the study cited was an expert opinion, review of the literature, or general survey that did not involve a specific patient cohort).

sociated with a significantly increased risk of thromboembolic events compared with patients who did not demonstrate a hyporesponse (60\% vs $3.6 \%$ ).

In 2015, Tan et al. ${ }^{46}$ reported on a retrospective, singlecenter study of 74 patients who underwent PED placement, with a goal of identifying risk factors for thromboembolic events. Using VerifyNow and a target preprocedural PRU of $<230$, patients in whom there was no response to clopidogrel were given an additional 600-mg dose of clopidogrel immediately after the procedure, but no procedures were delayed to achieve the target PRU. There was an observed trend toward increased thromboembolic events in those patients with a preprocedural PRU of $>208$, but this trend was not statistically significant.

Oran et al. ${ }^{36}$ performed a retrospective, single-center study of 100 consecutive patients treated with PED. Patients were divided into 2 groups: one group received tailored therapy based on PFT by multiple electrode aggregometry (Multiplate analyzer), while the other group did not undergo PFT and received no tailored therapy. Clopidogrel nonresponse was set at an area under the curve of $>468$. Treatment was tailored in this group with one of 3 alterations to the standard dual APT: ticlopidine, ticlopidine along with bridging intravenous tirofiban, or increased intraoperative intravenous heparin with no change in APT. Of the complications assessed in the 2 groups (thrombotic, hemorrhagic, and technical), the tailored therapy group that received PFT had significantly fewer thrombotic complications (0 vs 3 ). Of note, the 2 groups considered in this study were separated by a fixed point in time-untested patients earlier, followed by the group that received the PFT and tailored therapy-so the possibility remains that improved outcomes in the latter group were due to increased surgical experience.

McTaggart et al. ${ }^{34}$ performed a prospective, single-center study examining the use of TEG to measure platelet reactivity in 31 patients undergoing PED placement. All patients were started on a standard dual APT regimen of $75 \mathrm{mg}$ of clopidogrel and either $325 \mathrm{mg}$ or $81 \mathrm{mg}$ of aspirin daily for at least 7 days before the procedure. All patients were tested by TEG either before or on the day of the procedure, and a target therapeutic range of 30\%-0\% ADP-induced inhibition was set. Patients who were hyporesponsive (ADP-induced platelet inhibition of < 30\%) either received an additional preprocedural loading dose of $600 \mathrm{mg}$ of clopidogrel or they were transitioned to prasugrel with or without antiplatelet bridging via the GP-IIb/ IIIa antagonist Integrelin, depending on the proximity to the procedure. TEG testing resulted in APT modification in 12 patients (35\%), 11 of whom were found to be hyporesponders. Within the entire cohort, there were no hemorrhagic complications or new permanent neurological deficits, but there were still minor thromboembolic events in 3 patients and suspected transient ischemic attacks in 5 others. Among these patients who experienced thromboembolic or ischemic events, $75 \%$ were found to be clopidogrel hyporesponsive by TEG testing, with a cutoff of ADP-induced platelet response of $<30 \%$.

In 2016, Raychev et al. ${ }^{40}$ reported on a retrospective, single-center study to determine the strongest predictors of thrombotic and hemorrhagic complications associated with these procedures. Unique to this study, LTA was used as a noncommercial PFT to assess clopidogrelinduced ADP\% inhibition in 45 patients undergoing PED procedures. Although procedural duration as measured by fluoroscopy time was shown to have the greatest impact, ADP $\%$ inhibition of $>50 \%$ was also shown to have a significant association with thrombotic complications.

\section{Studies Critical or Unsupportive of the Use of PFT}

Conversely, studies demonstrating that routine PFT is unjustified identify substantial variability in PFT application and potential morbidity related to the use (Table 1). 
TABLE 2. Summary of selected articles from the cardiology literature

\begin{tabular}{lllllll}
\hline Authors \& Year & $\begin{array}{c}\text { Name of } \\
\text { Study }\end{array}$ & \multicolumn{1}{c}{ Methodology } & $\begin{array}{c}\text { No. of } \\
\text { Patients }\end{array}$ & $\begin{array}{c}\text { Level of } \\
\text { Evidence }\end{array}$ & Type of PFT Used & $\begin{array}{c}\text { Improved Outcomes Using } \\
\text { PFT or Tailored APT }\end{array}$ \\
\hline Price et al., 2011 & GRAVITAS & Randomized controlled trial & 2214 & B-R & VerifyNow & No \\
\hline Collet et al., 2012 & ARCTIC & Randomized controlled trial & 2440 & B-R & VerifyNow & No \\
\hline Aradi et al., 2013 & & Meta-analysis & 4213 & B-R & VerifyNow, VASP, LTA, or Multiplate & Yes \\
\hline Aradi et al., 2015 & & Position statement & - & E & VerifyNow, Multiplate, or VASP & No \\
\hline
\end{tabular}

$\mathrm{R}=$ randomized; $\mathrm{VASP}=$ vasodilator-stimulated phosphoprotein.

In 2013, separate commentaries by Chandra ${ }^{12}$ and Comin and Kallmes ${ }^{14}$ were published that both argued that, based on the available literature, particularly the large, randomized, controlled trials in the cardiology literature, routine PFT in the neurointerventional setting was unjustified. The following year, on behalf of the Society of Neurointerventional Surgery Standards and Guidelines Committee, Gandhi et al. ${ }^{22}$ produced a comprehensive review of the available cardiology and neurointerventional literature regarding APT and PFT to assess how these should be applied in the neurointerventional setting. Most of the evidence reviewed was Level B or Level C, including singlecenter randomized trials, nonrandomized studies, expert opinion, and case studies. The authors concluded that while the available cardiology and neurointerventional literature agreed that sub- and supratherapeutic platelet inhibition were associated with increased risk of thromboembolic and hemorrhagic complications, respectively, there was insufficient evidence to justify a recommendation of routine PFT before neurointerventional procedures.

Faught et al. ${ }^{18}$ published the results of a multicenter survey examining neuroendovascular practices in the United States related to the use of APT and PFT. They received 74 responses, $56.8 \%$ of which were from academic institutions. The results demonstrated significant heterogeneity in the practice patterns of neurointerventional surgeons regarding the type of APT used, dosing, perioperative duration, and use of PFT. The authors also proposed several potential explanations for this heterogeneity, including the increasing number of new antiplatelet medications entering the market and controversy within the literature surrounding the efficacy of PFT.

In 2015, Flechtenmacher et al. ${ }^{20}$ reported on a prospective, single-center study examining the correlation between clopidogrel-induced platelet inhibition measured by 3 popular PFT methods and the association of reported clopidogrel resistance with actual thromboembolic events. One hundred seven consecutive patients undergoing intraor extracranial stent placement or stent-assisted coiling of intracranial aneurysms were tested with all 3 methods being studied: LTA, VerifyNow, and Multiplate analyzer. All patients received a standard dual APT regimen consisting of $100 \mathrm{mg}$ of aspirin and $75 \mathrm{mg}$ of clopidogrel daily or they were given $600 \mathrm{mg}$ of clopidogrel the day before the procedure. If any 2 or all 3 of the tests indicated hyporesponsiveness to clopidogrel, the dose was increased to $150 \mathrm{mg}$ daily. Sixty-seven percent of the patients in the cohort were hyporesponsive to clopidogrel according to at least one test method, and 23\% were hyporesponsive ac- cording to all 3 tests. LTA testing was the most sensitive method $(77.8 \%)$ by which to predict thromboembolic complications, followed by VerifyNow (66.7\%) and Multiplate analyzer (44.4\%). The authors noted the complication rate of patients deemed hyporesponsive to clopidogrel by LTA was $14.3 \%$, compared with just $3.7 \%$ in patients determined to be responsive. Although LTA testing showed more promise than the other 2 PFT methods in this study, the differences reported failed to reach statistical significance.

Also in 2015, Brinjikji et al. ${ }^{8}$ used the International Retrospective Study of Pipeline Embolization Device registry to compare outcomes between patients receiving PFT and patients who did not have PFT prior to PED placement. They found that, even when differences in baseline characteristics like age, aneurysm size, and number of PEDs placed were controlled, patients receiving PFT experienced significantly higher rates of intracranial hemorrhage and neurological morbidity. Unfortunately, the database used did not provide any insight into why these patients received PFT. There are many other limitations to this study, including variable APT regimens, a lack of information about patient comorbidities, and a lack of information on what, if any, changes to therapy were made in response to PFT.

In 2016, Skukalek et al. ${ }^{45}$ published an extensive review and meta-analysis examining the impact of APT and PFT in patients treated with PED on the rates of thrombotic and hemorrhagic complications. Their analysis of 19 single-center and multicenter studies found no significant association between the use of PFT and the rates of symptomatic thrombotic or hemorrhagic complications with PED placement. Of these 19 studies, only 6 involved the consistent use of PFT, with a mix of VerifyNow, Multiplate, and platelet inhibition assays.

\section{PFT in the Cardiology Literature}

Compared with the neurosurgical and neurointerventional literature, the cardiology literature regarding APT and PFT is far more robust and includes several large, randomized, controlled trials (Table 2). One such study is the Gauging Responsiveness with A VerifyNow AssayImpact on Thrombosis and Safety (GRAVITAS) trial, ${ }^{38} \mathrm{a}$ multicenter, randomized, double-blind, active-control trial that compared the use of high-dose (600-mg loading dose, $150 \mathrm{mg}$ daily) and standard-dose (75 mg daily with no loading dose) clopidogrel treatment in patients with high on-treatment platelet reactivity following percutaneous 
coronary intervention. The GRAVITAS trial concluded that there was no significant difference between the standard- and high-dose clopidogrel groups in terms of reducing the incidence of the primary end points of death within 6 months by cardiovascular disease, nonfatal myocardial infarction, or stent thrombosis. Although high-dose clopidogrel was not shown to decrease morbidity and mortality rates compared with the standard dose, neither was it found to cause a significant increase in intracranial hemorrhage or moderate to severe bleeding events.

The GRAVITAS trial was followed by another landmark randomized, controlled trial known as ARCTIC (The Assessment by a Double Randomization of a Conventional Antiplatelet Strategy versus a Monitoring-guided Strategy for Drug-Eluting Stent Implantation and of Treatment Interruption versus Continuation One Year after Stenting). ${ }^{13}$ A total of 2440 lower-risk patients were randomized to receive platelet function monitoring with subsequent drug adjustments in those with a documented poor response to APT or conventional therapy without monitoring and medication adjustments. There was no statistically significant difference between the 2 treatment arms in regard to their primary outcomes (composite of death of any cause, myocardial infarction, stent thrombosis, stroke, or urgent revascularization within 1 year after initial treatment) or secondary outcomes (composite of stent thrombosis or urgent revascularization). Additionally, there was no difference in the rate of major bleeding events between the treatment arms. It is important to consider, however, that this was designed as a randomization of treatment strategy in lower-risk patients rather than a comparison of responders to platelet therapy versus nonresponders.

The following year, Janssen and ten Berg ${ }^{28}$ performed an extensive review of the literature to assess the efficacy of tailored APT with the use of PFT in stable patients undergoing percutaneous coronary intervention. They found no observable benefit from adjusting the antiplatelet regimen in this group when increasing clopidogrel dosage or adjunctive use of GP-IIb/IIIa inhibitors to correct for high on-treatment platelet reactivity. They also examined the potential use of more potent P2Y12 inhibitors in this group, such as prasugrel or ticagrelor, but concluded that the increased bleeding risk associated with these drugs might outweigh any potential improvement in the already low rates of thrombotic complications found in these patients.

A meta-analysis of randomized trials in the cardiology literature performed by Aradi et al. ${ }^{4}$ in 2013, however, indicated that platelet response testing and medication adjustments reduced the rates of thrombotic events during percutaneous coronary interventions compared with nontesting. There was no significant increase in major bleeding in the testing and nontesting cohorts. A meta-regression analysis indicated that the benefits of PFT were dependent on the patient's inherent risk of stent thrombosis, suggesting that testing might be better used in a subgroup of patients at elevated risk for thrombosis-related complications.

After a careful review of the available evidence, The Study Group on Biomarkers in Cardiology of the Acute Cardiovascular Care Associations of the European Society of Cardiology and the Working Group on Thrombosis of the European Society of Cardiology published a position statement in 2015 stating that there was no evidence that testing and modifying the antiplatelet regimen before percutaneous coronary interventions leads to improvements in outcomes. ${ }^{3}$ However, their recommendations were based on the use of prasugrel or ticagrelor as firstline agents rather than clopidogrel. For selected patients on clopidogrel, the utility of PFT in guiding therapy was uncertain.

\section{Conclusions}

PFT is an area of considerable controversy in both the neurointerventional and interventional cardiology realms. Our practice with flow diversion is derived predominantly from the initial trials with the PED (e.g., the PUFS trial) and the interventional cardiology literature, because there is insufficient evidence in the neurointerventional literature to recommend a standard strategy regarding PFT. Likewise, cardiology has been an early adopter of secondgeneration antiplatelet agents (prasugrel and ticagrelor), whereas most of the neurointerventional literature continues to focus on clopidogrel. Those of us who routinely use flow diversion as a treatment for cerebral aneurysms will continue to look toward the interventional cardiology literature for guidance to our future practice.

\section{References}

1. Alderazi YJ, Shastri D, Kass-Hout T, Prestigiacomo CJ, Gandhi CD: Flow diverters for intracranial aneurysms. Stroke Res Treat 2014:415653, 2014

2. Angiolillo DJ, Capranzano P, Goto S, Aslam M, Desai B, Charlton RK, et al: A randomized study assessing the impact of cilostazol on platelet function profiles in patients with diabetes mellitus and coronary artery disease on dual antiplatelet therapy: results of the OPTIMUS-2 study. Eur Heart J 29:2202-2211, 2008

3. Aradi D, Collet JP, Mair J, Plebani M, Merkely B, Jaffe AS, et al: Platelet function testing in acute cardiac care-is there a role for prediction or prevention of stent thrombosis and bleeding? Thromb Haemost 113:221-230, 2015

4. Aradi D, Komócsi A, Price MJ, Cuisset T, Ari H, Hazarbasanov D, et al: Efficacy and safety of intensified antiplatelet therapy on the basis of platelet reactivity testing in patients after percutaneous coronary intervention: systematic review and meta-analysis. Int J Cardiol 167:2140-2148, 2013

5. Bliden KP, DiChiara J, Tantry US, Bassi AK, Chaganti SK, Gurbel PA: Increased risk in patients with high platelet aggregation receiving chronic clopidogrel therapy undergoing percutaneous coronary intervention: is the current antiplatelet therapy adequate? J Am Coll Cardiol 49:657-666, 2007

6. Brandt JT, Close SL, Iturria SJ, Payne CD, Farid NA, Ernest CS II, et al: Common polymorphisms of CYP2C19 and CYP2C9 affect the pharmacokinetic and pharmacodynamic response to clopidogrel but not prasugrel. J Thromb Haemost 5:2429-2436, 2007

7. Breet NJ, van Werkum JW, Bouman HJ, Kelder JC, Ruven HJT, Bal ET, et al: Comparison of platelet function tests in predicting clinical outcome in patients undergoing coronary stent implantation. JAMA 303:754-762, 2010

8. Brinjikji W, Lanzino G, Cloft HJ, Siddiqui AH, Hanel RA, Kallmes DF: Platelet testing is associated with worse clinical outcomes for patients treated with the Pipeline embolization device. AJNR Am J Neuroradiol 36:2090-2095, 2015

9. Cattaneo M: Mechanisms of variability in antiplatelet agents response. Thromb Res 130 (Suppl 1):S27-S28, 2012 
10. Cattaneo M: Resistance to anti-platelet agents. Thromb Res 127 (Suppl 3):S61-S63, 2011

11. Chalouhi N, Jabbour P, Daou B, Starke RM, Shields B, Hasan DM: A new protocol for anticoagulation with tirofiban during flow diversion. Neurosurgery 78:670-674, 2016

12. Chandra RV: Point of care platelet function testing in routine neurointerventional care is unjustified. J Neurointerv Surg 5:280-282, 2013

13. Collet JP, Cuisset T, Rangé G, Cayla G, Elhadad S, Pouillot $\mathrm{C}$, et al: Bedside monitoring to adjust antiplatelet therapy for coronary stenting. N Engl J Med 367:2100-2109, 2012

14. Comin J, Kallmes DF: Platelet-function testing in patients undergoing neurovascular procedures: caught between a rock and a hard place. AJNR Am J Neuroradiol 34:730-734, 2013

15. Corredor C, Wasowicz M, Karkouti K, Sharma V: The role of point-of-care platelet function testing in predicting postoperative bleeding following cardiac surgery: a systematic review and meta-analysis. Anaesthesia 70:715-731, 2015

16. Delgado Almandoz JE, Crandall BM, Scholz JM, Fease JL, Anderson RE, Kadkhodayan Y, et al: Pre-procedure P2Y12 reaction units value predicts perioperative thromboembolic and hemorrhagic complications in patients with cerebral aneurysms treated with the Pipeline Embolization Device. J Neurointerv Surg 5 (Suppl 3):iii3-iii10, 2013

17. Delgado Almandoz JE, Kadkhodayan Y, Crandall BM, Scholz JM, Fease JL, Tubman DE: Variability in initial response to standard clopidogrel therapy, delayed conversion to clopidogrel hyper-response, and associated thromboembolic and hemorrhagic complications in patients undergoing endovascular treatment of unruptured cerebral aneurysms. J Neurointerv Surg 6:767-773, 2014

18. Faught RWF, Satti SR, Hurst RW, Pukenas BA, Smith MJ: Heterogeneous practice patterns regarding antiplatelet medications for neuroendovascular stenting in the USA: a multicenter survey. J Neurointerv Surg 6:774-779, 2014

19. Femia EA, Pugliano M, Podda G, Cattaneo M: Comparison of different procedures to prepare platelet-rich plasma for studies of platelet aggregation by light transmission aggregometry. Platelets 23:7-10, 2012

20. Flechtenmacher N, Kämmerer F, Dittmer R, Budde U, Michels P, Röther J, et al: Clopidogrel resistance in neurovascular stenting: correlations between light transmission aggregometry, VerifyNow, and the Multiplate. AJNR Am J Neuroradiol 36:1953-1958, 2015

21. Frelinger AL III, Furman MI, Linden MD, Li Y, Fox ML, Barnard MR, et al: Residual arachidonic acid-induced platelet activation via an adenosine diphosphate-dependent but cyclooxygenase-1- and cyclooxygenase-2-independent pathway: a 700-patient study of aspirin resistance. Circulation 113:2888-2896, 2006

22. Gandhi CD, Bulsara KR, Fifi J, Kass-Hout T, Grant RA, Delgado Almandoz JE, et al: Platelet function inhibitors and platelet function testing in neurointerventional procedures. J Neurointerv Surg 6:567-577, 2014

23. Garasic JM, Edelman ER, Squire JC, Seifert P, Williams MS, Rogers C: Stent and artery geometry determine intimal thickening independent of arterial injury. Circulation 101:812-818, 2000

24. Gurbel PA, Bliden KP, Guyer K, Cho PW, Zaman KA, Kreutz $\mathrm{RP}$, et al: Platelet reactivity in patients and recurrent events post-stenting: results of the PREPARE POST-STENTING Study. J Am Coll Cardiol 46:1820-1826, 2005

25. Gutensohn K, Beythien C, Bau J, Fenner T, Grewe P, Koester R, et al: In vitro analyses of diamond-like carbon coated stents. Reduction of metal ion release, platelet activation, and thrombogenicity. Thromb Res 99:577-585, 2000

26. Harmsze AM, van Werkum JW, Ten Berg JM, Zwart B, Bouman HJ, Breet NJ, et al: CYP2C19*2 and CYP2C9*3 alleles are associated with stent thrombosis: a case-control study. Eur Heart J 31:3046-3053, 2010

27. Jakubowski JA, Payne CD, Li YG, Brandt JT, Small DS, Farid NA, et al: The use of the VerifyNow P2Y12 point-ofcare device to monitor platelet function across a range of P2Y12 inhibition levels following prasugrel and clopidogrel administration. Thromb Haemost 99:409-415, 2008

28. Janssen PWA, ten Berg JM: Platelet function testing and tailored antiplatelet therapy. J Cardiovasc Transl Res 6:316328,2013

29. Jeong YH, Kim IS, Park Y, Kang MK, Koh JS, Hwang SJ, et al: Carriage of cytochrome 2C19 polymorphism is associated with risk of high post-treatment platelet reactivity on high maintenance-dose clopidogrel of $150 \mathrm{mg} /$ day: results of the ACCEL-DOUBLE (Accelerated Platelet Inhibition by a Double Dose of Clopidogrel According to Gene Polymorphism) study. JACC Cardiovasc Interv 3:731-741, 2010

30. Jilma B: Platelet function analyzer (PFA-100): a tool to quantify congenital or acquired platelet dysfunction. J Lab Clin Med 138:152-163, 2001

31. Kovács EG, Katona E, Bereczky Z, Homoródi N, Balogh L, Tóth E, et al: New direct and indirect methods for the detection of cyclooxygenase 1 acetylation by aspirin; the lack of aspirin resistance among healthy individuals. Thromb Res 131:320-324, 2013

32. Lee SW, Park SW, Hong MK, Kim YH, Lee BK, Song JM, et al: Triple versus dual antiplatelet therapy after coronary stenting: impact on stent thrombosis. J Am Coll Cardiol 46:1833-1837, 2005

33. Mallouk N, Labruyère C, Reny JL, Chapelle C, Piot M, Fontana $\mathrm{P}$, et al: Prevalence of poor biological response to clopidogrel: a systematic review. Thromb Haemost 107:494-506, 2012

34. McTaggart RA, Choudhri OA, Marcellus ML, Brennan T, Steinberg GK, Dodd RL, et al: Use of thromboelastography to tailor dual-antiplatelet therapy in patients undergoing treatment of intracranial aneurysms with the Pipeline embolization device. J Neurointerv Surg 7:425-430, 2015

35. Mega JL, Close SL, Wiviott SD, Shen L, Hockett RD, Brandt JT, et al: Cytochrome P450 genetic polymorphisms and the response to prasugrel: relationship to pharmacokinetic, pharmacodynamic, and clinical outcomes. Circulation 119:2553-2560, 2009

36. Oran I, Cinar C, Bozkaya H, Korkmaz M: Tailoring platelet inhibition according to multiple electrode aggregometry decreases the rate of thrombotic complications after intracranial flow-diverting stent implantation. J Neurointerv Surg 7:357-362, 2015

37. Paniccia R, Priora R, Liotta AA, Abbate R: Platelet function tests: a comparative review. Vasc Health Risk Manag 11:133-148, 2015

38. Price MJ, Berger PB, Teirstein PS, Tanguay JF, Angiolillo DJ, Spriggs D, et al: Standard- vs high-dose clopidogrel based on platelet function testing after percutaneous coronary intervention: the GRAVITAS randomized trial. JAMA 305:1097-1105, 2011 (Erratum JAMA 305:2174, 2011)

39. Raju NC, Eikelboom JW, Hirsh J: Platelet ADP-receptor antagonists for cardiovascular disease: past, present and future. Nat Clin Pract Cardiovasc Med 5:766-780, 2008

40. Raychev R, Tateshima S, Vinuela F, Sayre J, Jahan R, Gonzalez N, et al: Predictors of thrombotic complications and mass effect exacerbation after pipeline embolization: The significance of adenosine diphosphate inhibition, fluoroscopy time, and aneurysm size. Interv Neuroradiol 22:34-41, 2016

41. Santilli F, Rocca B, De Cristofaro R, Lattanzio S, Pietrangelo L, Habib A, et al: Platelet cyclooxygenase inhibition by lowdose aspirin is not reflected consistently by platelet function assays: implications for aspirin "resistance". J Am Coll Cardiol 53:667-677, 2009 
42. Schwartz KA, Schwartz DE, Ghosheh K, Reeves MJ, Barber $\mathrm{K}$, DeFranco A: Compliance as a critical consideration in patients who appear to be resistant to aspirin after healing of myocardial infarction. Am J Cardiol 95:973-975, 2005

43. Siller-Matula JM, Delle-Karth G, Lang IM, Neunteufl T, Kozinski M, Kubica J, et al: Phenotyping vs. genotyping for prediction of clopidogrel efficacy and safety: the PEGASUSPCI study. J Thromb Haemost 10:529-542, 2012

44. Siller-Matula JM, Trenk D, Schrör K, Gawaz M, Kristensen $\mathrm{SD}$, Storey RF, et al: Response variability to $\mathrm{P} 2 \mathrm{Y} 12$ receptor inhibitors: expectations and reality. JACC Cardiovasc Interv 6:1111-1128, 2013

45. Skukalek SL, Winkler AM, Kang J, Dion JE, Cawley CM, Webb A, et al: Effect of antiplatelet therapy and platelet function testing on hemorrhagic and thrombotic complications in patients with cerebral aneurysms treated with the pipeline embolization device: a review and meta-analysis. J Neurointerv Surg 8:58-65, 2016

46. Tan LA, Keigher KM, Munich SA, Moftakhar R, Lopes DK: Thromboembolic complications with Pipeline Embolization Device placement: impact of procedure time, number of stents and pre-procedure P2Y12 reaction unit (PRU) value. J Neurointerv Surg 7:217-221, 2015

47. Wallentin L, Becker RC, Budaj A, Cannon CP, Emanuelsson $\mathrm{H}$, Held C, et al: Ticagrelor versus clopidogrel in patients with acute coronary syndromes. N Engl J Med 361:10451057,2009
48. Wiviott SD, Braunwald E, McCabe $\mathrm{CH}$, Montalescot G, Ruzyllo W, Gottlieb S, et al: Prasugrel versus clopidogrel in patients with acute coronary syndromes. N Engl J Med 357:2001-2015, 2007

49. Yang H, Li Y, Jiang Y, Lv X: Thromboelastography for monitoring platelet function in unruptured intracranial aneurysm patients undergoing stent placement. Interv Neuroradiol 21:61-68, 2015

\section{Disclosures}

Dr. Taussky is a proctor/consultant for Medtronic.

\section{Author Contributions}

Conception and design: Park, Taylor. Acquisition of data: Park, Taylor. Drafting the article: Park, Taylor, Dickerson, Dambrino. Critically revising the article: Park, Kalani, Taussky, Washington. Reviewed submitted version of manuscript: Park. Approved the final version of the manuscript on behalf of all authors: Park.

\section{Correspondence}

Min S. Park, Department of Neurosurgery, Clinical Neurosciences Center, University of Utah, 175 N Medical Dr. East, Salt Lake City, UT 84132. email: neuropub@hsc.utah.edu. 